\title{
Predictive Factors for Viral B and C Infection in Health Workers in a University Hospital in Ivory Cost
}

\author{
Okon Anassi Jean-Baptiste, Koné Amadou, Diakité Mamadou, Aké Fabrice, \\ Thot'o Amani Sroboua, N'dri N'guessan
}

Hepato-Gastroenterology Department, University Hospital Center, Bouaké, Ivory Coast

Email: okonanassi@yahoo.fr

How to cite this paper: Jean-Baptiste, O.A., Amadou, K., Mamadou, D., Fabrice, A., Sroboua, T.A. and N'guessan, N. (2018) Predictive Factors for Viral B and C Infection in Health Workers in a University Hospital in Ivory Cost. Open Journal of Gastroenterology, 8, 377-385.

https://doi.org/10.4236/ojgas.2018.810039

Received: August 5, 2018

Accepted: October 21, 2018

Published: October 24, 2018

Copyright $\odot 2018$ by authors and Scientific Research Publishing Inc. This work is licensed under the Creative Commons Attribution International License (CC BY 4.0).

http://creativecommons.org/licenses/by/4.0/

\begin{abstract}
Purpose: To evaluate the serological status of hepatitis $\mathrm{B}$ and $\mathrm{C}$ and to identify the risk factors for viral $\mathrm{B}$ and $\mathrm{C}$ infection in health workers at the university hospital. Material and Method: Mono-centric cross-sectional study carried out at Bouaké University Hospital from March 2nd to May 16th, 2016, concerning the health staff of the Bouake University Hospital. Cross-sectional study mono-centric concerning the serological status of viral hepatitis B and C from the period from March 2nd to May 16th, 2016 of the health staff of the University Hospital of Bouaké. It has benefited from data from PNLHVi (national program against viral hepatitis) as part of its awareness campaign. The data were analyzed by SPSS software version 20.0. Results: Of the 1107 health workers, 632 had been included, representing a participation rate of $57.1 \%$. The average age of the staff was 37.8 years with extremes ranging from 18 to 66 years. The sex ratio (H/F) was 0.8 . Accidents with blood exposure were noted in $52.4 \%$ of cases. The maximum vaccine coverage was $16.1 \%$. The prevalence of HBsAg was $8.4 \%$. Contact with HBV was present in $3 / 4$ of the staff. Anti HCV Ab was positive in $1.4 \%$ of the staff. Males, age over 50 and over 20 years of seniority were associated with HBV. Also, HBV infection was significantly higher in boys and girls (81.7\%), nurses (78.3\%) and nursing aides (73.8\%), $(\mathrm{p}=0.022)$. HCV infection was significantly correlated with emergency services. Conclusion: Age, gender, seniority, paramedic qualification, and high risk of exposure to body fluids were correlated with viral B infection while emergency department membership was a factor risk of HCV infection.
\end{abstract}

\section{Keywords}

Prevalence, Risk Factors, Viral Hepatitis B, Viral Hepatitis C, 


\section{Introduction}

Viral hepatitis B (HBV) and Viral hepatitis C (HCV) pose a public health problem in the world especially in low-income countries with about 350,000 to 500,000 deaths per year [1] [2] [3]. Approximately 36 million health workers are victims each year of a work incident that exposes nearly 3 million to the risk of contamination by hepatitis B and C viruses [3]. In the course of their duties, health care workers are frequently exposed to HBV and HCV and it is estimated that approximately $75 \%$ of the overall exposure risk is transcutaneous compared to only one quarter for the cutaneous route; mucosa, with a higher risk of contamination for the transcutaneous route [1].

There are 3 degrees of contamination according to the causal link established between the medical staff and their patient:

- the transmission is confirmed when there is an epidemiological link and especially a confirmation by the presence of partial or complete sequence of similar DNA between the staff and their patient,

- the transmission is said probable if the genotype of the virus of the personnel and its patient is identical and that there is an epidemiological link between them,

- transmission is possible if there is an epidemiological link between the staff and their patient, the patient has no other risk factor for contamination and it is not possible to carry out a correspondence between pathogens [2].

Although several studies have reported the prevalence of HBV and HCV infections in different risk groups, so far there is little or no published data on the prevalence and risk factors of viral infection. B and C taking into account all health personnel in Côte d'Ivoire. Thus, this study aimed mainly at determining the seroprevalence of HBV and HCV infections and the associated risk factors among health workers at the University Hospital Center (CHU) in Bouaké, Côte d'Ivoire.

\section{Material and Method}

It is a cross-sectional mono-centric study with descriptive and analytical aims. The study took place from March 2nd to May 16th 2016 at the Bouake University Hospital. Included in the study were health personnel (medical, paramedical) from the Bouaké University Hospital, who were present at the facility during the study period and gave their oral informed consent to the investigator. Administrative, technical and trainee staff were not selected for this study.

\subsection{The Study Protocol}

This study benefited from the work of PNLHVi (national program against viral 
hepatitis) as part of its awareness campaign, which we inherited data. The study was conducted in two phases (a clinical phase and a biological phase).

The clinical phase was held from 02 to 16 March 2016 and consisted of a questioning of the health worker using a questionnaire that provided information on: its socio-professional characteristics (age, sex, service, qualification and seniority).

The services were classified according to the nature of the care provided in 5 groups which are:

- medical services;

- surgery services;

- the mother-child block that contained gynecology-obstetrics and pediatrics;

- medical and surgical emergencies;

- para-clinical services (radiology and laboratory).

The qualification was split into 2 groups:

- medical staff composed of doctors and surgeons;

- paramedical staff represented by nurses, midwives, caregivers, waiters, lab technicians and radiology and rehabilitation technicians.

Exposure of health workers was divided into 2 groups according to the risk of repeated and frequent contact with biological fluids:

* a high-risk group for exposure to body fluids consisting of surgeons, nurses, midwives, caregivers, waiters and lab technicians;

* a group at low risk of exposure including physicians, and radiology and rehabilitation technicians;

- his past medical history, namely the concept of previous transfusion, blood exposure accidents, and his vaccination status with respect to viral hepatitis B.

The biological phase; It followed the clinical phase and lasted until May 16, 2016. For each agent interviewed, a venous blood sample of 5 to $8 \mathrm{ml}$ on a dry tube was made by phlebotomists made available by the department. Laboratory of the University Hospital of Bouaké. This sample is then stored in a cooler at a temperature of $15^{\circ} \mathrm{C}$ to $20^{\circ} \mathrm{C}$ before being sent to the biochemistry laboratory of the University Hospital of Bouake for analysis. Once in the laboratory, the samples were centrifuged at $3000 \mathrm{rpm}$ for 10 minutes, then the qualitative assay of $\mathrm{HBsAg}, \mathrm{HBcAb}$ and $\mathrm{HCV}$ anti-Ab was carried out by the sandwich method with ECL technique using COBAS, then the samples were aliquoted for conservation (Serotec) before validation of the results by the assistants of the service.

\subsection{Statistics}

The data collected on the survey sheets were saved in an Excel file and then transferred for processing into the SPSS version 20.0 analysis software. A comparison of observed proportions was made from the KHI two tests and the $\mathrm{p}$-value (significance level) was significant if it was less than 0.05 . 


\subsection{Ethics}

The study had obtained the agreement of the ethics committee, the heads of department and that of the Director of the University Hospital Center of Bouaké. The protocol was explained to the different $\mathrm{CHU}$ agents before his oral consent. The questionnaire was anonymous.

\subsection{Results}

Of the 1107 health workers of the University Hospital of Bouake, 632 were randomized to either a participation rate of $57.1 \%$. The general characteristics of the 632 health workers are summarized in Table 1.

The average age of staff at Bouaké University Hospital was 37.8 years with extremes ranging from 18 to 66 years. Women predominated with a sex ratio $(\mathrm{M} / \mathrm{F})$ of 0.87 . The services that participated massively were those of the gynecology-obstetrics/pediatrics block with $28 \%$ of participants, medicine with $27.7 \%$ of participants and surgery with $24.7 \%$ of participants. Health workers with less than 10 years of seniority accounted for $74.2 \%$ of the study population. Nursing aids and nurses with $32.6 \%$ of cases and $22.6 \%$ of cases respectively were the most numerous. Health workers at high risk of contact with body fluids were the most numerous with $75 \%$ of participants. In $3.6 \%$ of cases, health workers had a history of blood transfusion. Health workers had a blood exposure accident in $52.4 \%$ of cases. Health workers had responded be vaccinated in $46.4 \%$ of cases. Among them, 102 had made the 3 recommended doses, ie a maximum vaccination coverage of $16.1 \%$. HBsAg was positive in $8.4 \%$ of health workers and HCV-positive anti was positive in $1.4 \%$ of health workers. Contact with HBV was $72.6 \%$ of the nearly 3 quarters of the staff. Les predictors of viral infection $\mathrm{B}$ and $\mathrm{C}$ are summarized in Table 2 and Table 3.

The HBsAg was higher in men significantly. The positivity of HBsAg was higher respectively in the para-clinical services in $13.1 \%$ of cases in emergency services in $11.1 \%$ of cases and $10.3 \%$ in medical cases not significantly. With a prevalence of $23.1 \%$, health workers with 26 to 30 years of seniority were the most affected by HVB. Health workers are who reported being vaccinated against HBV and who had HBsAg accounted for $7.5 \%$ of cases. HBV contact was higher among health workers over 50 years of age significantly. HBV contact was higher in men than in women significantly. HBV contact was more important in surgery than in medicine in a non-significant way. Health workers most in contact with HBV were those who had a seniority of over 35 years (100\%), between 31 and 35 years (90\%) and between 21 and 25 years (90\%). Contact HBV was significantly higher respectively in boys and girls of room in $81.7 \%$ of cases, nurses in $78.3 \%$ of patients and nursing aids in $73.8 \%$ of cases. Also contact HBV was significant higher among health workers at risk of high exposure to body fluids in $74.6 \%$ of cases. In multivariate analysis, age over 40 years, males, seniority over 25 , paramedical qualification, and high risk of exposure to body fluids were significantly associated with HBV infection. 
Table 1. General characteristics and seroprevalence of VHB_VHC infection in care staff at the Bouaké University Hospital.

\begin{tabular}{|c|c|c|c|c|c|}
\hline Variables & Total & $\begin{array}{c}\text { HVB negative } \\
\text { n \% }\end{array}$ & $\begin{array}{c}\text { HVB positive } \\
\text { n } \%\end{array}$ & $\begin{array}{c}\text { HVC negative } \\
\mathrm{n} \%\end{array}$ & $\begin{array}{c}\text { HVC positive } \\
\text { n } \%\end{array}$ \\
\hline \multicolumn{6}{|l|}{ Sex } \\
\hline feminine & 338 & $107 / 31.7 \%$ & $231 / 68.3 \%$ & $334 / 98.8 \%$ & $4 / 1.2 \%$ \\
\hline masculine & 294 & $64 / 21.8 \%$ & $230 / 78.2 \%$ & $289 / 98.3 \%$ & $5 / 1.7 \%$ \\
\hline \multicolumn{6}{|l|}{ Ages } \\
\hline$<20$ years & 1 & $0 / 0 \%$ & $1 / 100 \%$ & $1 / 100 \%$ & $0 / 0 \%$ \\
\hline [20 - 29] years & 74 & $28 / 37.8 \%$ & $46 / 62.2 \%$ & $74 / 100 \%$ & $0 / 0 \%$ \\
\hline [30 - 39] years & 345 & $98 / 28.4 \%$ & $247 / 71.6 \%$ & $340 / 98.6 \%$ & $5 / 1.4 \%$ \\
\hline$[40-68]$ years & 212 & $45 / 21.2 \%$ & $167 / 78.8 \%$ & $208 / 98.1 \%$ & $4 / 1.9 \%$ \\
\hline \multicolumn{6}{|l|}{ Qualification: } \\
\hline Nursing aids & 206 & $53 / 25.7 \%$ & $153 / 74.3 \%$ & $204 / 99 \%$ & $2 / 1 \%$ \\
\hline Surgeons & 55 & $19 / 34.5 \%$ & $36 / 65.5 \%$ & $54 / 98.2 \%$ & $1 / 1.8 \%$ \\
\hline Boys-girls of room & 82 & $15 / 18.3 \%$ & $67 / 81.7 \%$ & $80 / 97.6 \%$ & $2 / 2.4 \%$ \\
\hline Nurses & 143 & $31 / 21.7 \%$ & $112 / 78.3 \%$ & $141 / 98.6 \%$ & $2 / 1.4 \%$ \\
\hline Doctors & 63 & $26 / 41.3 \%$ & $37 / 58.7 \%$ & $62 / 98.4 \%$ & $1 / 1.6 \%$ \\
\hline Midwives & 45 & $14 / 31.1 \%$ & $31 / 68.9 \%$ & $44 / 100 \%$ & $0 / 0 \%$ \\
\hline Laboratory technician & 25 & $7 / 28 \%$ & $18 / 72 \%$ & $24 / 96 \%$ & $1 / 4 \%$ \\
\hline $\begin{array}{c}\text { Radiology and } \\
\text { Rehabilitation } \\
\text { Technician }\end{array}$ & 13 & $6 / 46.2 \%$ & $7 / 53.8 \%$ & $13 / 100 \%$ & $0 / 0 \%$ \\
\hline \multicolumn{6}{|l|}{ Department: } \\
\hline Surgery & 156 & $36 / 23.1 \%$ & $120 / 76.9 \%$ & $155 / 99.4 \%$ & $1 / 0.6 \%$ \\
\hline $\begin{array}{l}\text { gynecology and } \\
\text { pediatrics }\end{array}$ & 177 & $49 / 27.7 \%$ & $128 / 72.3 \%$ & $175 / 98.9 \%$ & $2 / 1.1 \%$ \\
\hline Medicine & 175 & $51 / 29.1 \%$ & $124 / 70.9 \%$ & $174 / 99.4 \%$ & $1 / 0.6 \%$ \\
\hline Paraclinical & 61 & $17 / 27.9 \%$ & $44 / 72.1 \%$ & $59 / 96.7 \%$ & $2 / 3.3 \%$ \\
\hline Emergencies & 63 & $18 / 28.6 \%$ & $45 / 71.4 \%$ & $60 / 95.2 \%$ & $3 / 4.8 \%$ \\
\hline \multicolumn{6}{|l|}{ Transfusion: } \\
\hline No & 609 & $167 / 27.4 \%$ & $442 / 72.6 \%$ & $600 / 98.5 \%$ & $9 / 1.5 \%$ \\
\hline Yes & 23 & $4 / 17.4 \%$ & $19 / 82.6 \%$ & $23 / 9100 \%$ & $0 / 0 \%$ \\
\hline \multicolumn{6}{|l|}{ Degree of exposure: } \\
\hline High & 474 & $124 / 26.2 \%$ & $350 / 73.8 \%$ & $468 / 98.7 \%$ & $6 / 1.3 \%$ \\
\hline Low & 158 & $47 / 29.7 \%$ & $111 / 70.3 \%$ & $155 / 98.1 \%$ & $3 / 1.9 \%$ \\
\hline \multicolumn{6}{|l|}{ Vaccination: } \\
\hline No & 339 & $77 / 22.7 \%$ & $262 / 77.3 \%$ & $335 / 98.8 \%$ & $4 / 1.2 \%$ \\
\hline Yes & 293 & $94 / 32.1 \%$ & $199 / 67.9 \%$ & $288 / 98.3 \%$ & $5 / 1.7 \%$ \\
\hline \multicolumn{6}{|l|}{ Seniority: } \\
\hline$<10$ years & 469 & $134 / 28.6 \%$ & $335 / 71.4 \%$ & $464 / 98.9 \%$ & $5 / 1.1 \%$ \\
\hline$[10-19]$ years & 95 & $27 / 28.4 \%$ & $68 / 71.6 \%$ & $94 / 98.9 \%$ & $1 / 1.1 \%$ \\
\hline [20 - 29] years & 46 & $9 / 19.6 \%$ & $37 / 80.4 \%$ & $44 / 95.7 \%$ & $2 / 4.3 \%$ \\
\hline [30 - 39] years & 19 & $1 / 5.3 \%$ & $18 / 94.7 \%$ & $19 / 100 \%$ & $0 / 0 \%$ \\
\hline [40 - 49] years & 3 & $0 / 0 \%$ & $3 / 100 \%$ & $2 / 66.7 \%$ & $1 / 33.3 \%$ \\
\hline
\end{tabular}


Table 2. Correlation between factors predictive of viral infection B (contact-infection) and positivity of viral markers $B$.

\begin{tabular}{cccc}
\hline Variables & $\mathrm{p}$ & $0 \mathrm{R}$ & $\mathrm{IC}$ \\
\hline Sex: Féminine vs masculine & $\mathbf{0 . 0 0 3}$ & $\mathbf{1 . 6 6}$ & $\mathbf{1 . 1 6 - 2 . 3 8}$ \\
Age: $<40$ years vs $\geq \mathbf{4 0}$ years & $\mathbf{0 . 0 1 6}$ & $\mathbf{1 . 5 9}$ & $\mathbf{1 . 0 7 - 2 . 3 5}$ \\
Qualification: Medical vs paramedical & 0.002 & 1.22 & $1.05-1.42$ \\
Department & & & \\
-Paramedical vs medical & 0.49 & 0.96 & $0.53-1.72$ \\
-Emergencies vs hospitalization & 0.35 & 1.09 & $0.76-1.54$ \\
Seniority $<30$ years vs $\geq 30$ years & $\mathbf{0 . 0 0 8}$ & $\mathbf{8 . 1 1}$ & $\mathbf{1 . 0 8 - 6 0 . 7 9}$ \\
\hline
\end{tabular}

Table 3. Correlation between factors predictive of viral infection $\mathrm{C}$ and positivity of viral markers C.

\begin{tabular}{cccc}
\hline Variables & $\mathrm{p}$ & $0 \mathrm{R}$ & $\mathrm{IC}$ \\
\hline Sex: Féminine vs masculine & 0.41 & 1.45 & $0.38-5.43$ \\
Age: $<40$ years vs $\geq 40$ years & 0.35 & 1.59 & $0.42-6.01$ \\
Qualification: Medical vs paramedical & 0.52 & 1.25 & $0.27-6.09$ \\
Department & & & \\
-Paramedical vs medical & 0.21 & 2.73 & $0.55-13.45$ \\
-Emergencies vs hospitalization & $\mathbf{0 . 0 0 7}$ & $\mathbf{8 . 2 3}$ & $\mathbf{1 . 3 5}-\mathbf{5 0 . 3 0}$ \\
Seniority $<30$ years vs $\geq 30$ years & 0.27 & 3.58 & $0.43-29.97$ \\
\hline
\end{tabular}

For contact with HCV, it was higher among health workers over 50 in $2.74 \%$ of cases. HCV contact was higher in men than in women. The agents most in contact with HCV were those who had more than 35 years of seniority in $10 \%$ of cases. HCV contact was higher for laboratory technicians in $4 \%$ of cases and for boys and girls in $2.4 \%$ of cases. HCV contact was greatest among health workers with low risk of exposure to body fluids. HCV infection was predominant among workers over 50 years, men in emergency departments, over 35 years of seniority, among laboratory technicians. However, there was no significant relationship between viral $\mathrm{C}$ infection and these variables in multivariate univariate analysis, whereas $\mathrm{HCV}$ infection was significantly correlated with emergency services $(p=0.007 ; 8.23[1.35-50.30])$.

\section{Discussion}

The age group of 30 to 40 years is the one found in the work in Africa and the Middle East [4] [5] [6]. The sex ratio close to 1 seems to reflect the gender parity advocated by our leaders in the employment sector [6] [7] [8]. Nurses and nursing aids made up the population at risk for exposure to body fluids as mentioned in the literature [7] [9] [10] [11]. More than half of the health workers in this study had been exposed to body fluids, Bathaix had an blood exposure accidents in $34.6 \%$ of health staff [12]. According to the World Health Organization (WHO), 
the misapplication of universal measures to prevent infections in hospital settings [1]. Immunization coverage of health workers at Bouaké University Hospital was $16.1 \%$, a low coverage, contrary to data from the literature [6] [7] [10] [13]. In Saudi Arabia, extensive vaccination campaigns undertaken by the Kingdom in the 1990s to reduce the prevalence of HBV resulted in a high proportion of health workers (84.7\%) who received one vaccine dose in the 5 years before the study [6]. For African countries, it is only recently that most of these countries have systematically included HBV vaccination in their immunization program [1]. The prevalence of HBsAg of health staff at Bouaké University Hospital was 8.4\%. This prevalence was close to that found in blood donors in Bouaké (12.5\%) [14] and consistent with data from the literature in African countries [5] [8] [13]. Nearly three-quarters of the study population had contact with HBV as in most African countries in highly endemic areas [15]. The risk of HBV infection was significantly related to the seniority of health workers and the male sex as observed in previous work [5] [6] [8]. Indeed, several authors agree that seniority was correlated with the positivity of HBsAg. And this seniority threshold varied according to the country. In this study, it was 25 years old when in Tanzania and Uganda this threshold was 10 years old [8] [13] [16]. The increase in the prevalence of HBV with age and seniority can be explained by the combination of the risks of contact with the virus as well as in the working life. According to the WHO, the risk of viral B infection is greater in case of impaired reflexes on universal measures of infection prevention and in case of increased exposure to blood exposure accidents [1] [16]. In this study, paraclinical services and emergencies were most affected by $\mathrm{HBV}$, unlike in Uganda, where HBsAg positivity was predominant in medical services. Depending on the qualification of the agents, the study identifies 3 corporations with prevalences of HBV greater than $10 \%$. These are surgeons (10.9\%), nurses (11.2\%) and radiology and rehabilitation technicians (23.1\%). Mueller in Tanzania found that doctors and nurses had a significantly higher prevalence of HBsAg compared to other professions [13]. In the United States [9] and Burkina Faso [8], authors have significantly demonstrated a higher prevalence of HBsAg, respectively, in nurses and surface technicians. Of all these studies, the nursing corps was regularly cited as health workers who had a high prevalence of HBsAg. There was no significant link between viral contact B and the health worker service. Due to the permanent rotations of the paramedical staff in the different services. But HBV contact was significantly higher among paramedics than nursing aids, room boys and girls and nurses $(\mathrm{p}=0.022)$ as described by several authors [5] [8] [12] [16]. Paramedical staff being more exposed to body fluids is often a victim of blood exposure accidentsin the practice of their profession. Thus, according to Bathaix, nurses were more exposed to blood exposure accidents [12]. The high prevalence of contact among ward boys and girls and caregivers could be explained by a poor knowledge of the risks of infection by them and also by the lack of knowledge of the universal measures of infection prevention in hospital settings. Also in our context, room boys and girls 
as well as nursing aids tend to perform the tasks usually reserved for nurses, exposing them a little more to HBV.

The prevalence of HCV among health workers at Bouaké University Hospital was $1.4 \%$. This result was consistent with literature data both in the US and in Africa [9] [15] [17]. But this value is lower than the 4.4\% found in blood donors in Abidjan from 1997 to 2012 [18]. The positivity of the Anti-HCV Ab was correlated with the health workers' membership of the emergency services. This high risk of exposure is explained by the fact that they are constantly engaged in repeated invasive procedures and some emergency situations bring health workers to procedural errors in the implementation of universal prevention measures infections in hospital settings [1] [16]. On the other hand, neither age, sex, seniority, qualification and high risk of contact with body fluids were correlated with HCV infection.

The limit of this study may be that when screening many agents were absent or some refused to participate. Absence of markers that can verify vaccination. But nevertheless this study provides important results.

\section{Conclusion}

The prevalence of HBsAg among health workers at Bouake University Hospital was $8.4 \%$ and that of $\mathrm{HCV}$ was $1.4 \%$. Emergency services were an important source of HCV infection. The paramedical qualification, especially the nurses, the boys and girls of rooms as well as the carers, constitutes the professional layer at risk of HBV infection because of their function on the one hand and on the other hand of their ignorance of the measures prevent against these viruses. In the control of viral hepatitis $\mathrm{B}$ and $\mathrm{C}$ in health workers, systematic screening and vaccination against HBV of naive subjects should be carried out before the exercise of the function as well as reinforcement of the preventive measures of theblood exposure accidents.

\section{Conflicts of Interest}

The authors declare no conflicts of interest regarding the publication of this paper.

\section{References}

[1] WHO/VHB (2015) Guidelines for the Prevention, Care and Treatment of Persons with Chronic Hepatitis B Infection.

[2] Lewis, J.D., Anfield, K.B. and Sifri, C.D. (2015) Hepatitis B in Healthcare Workers: Transmission Events and Guidance for Management. World Journal of Hepatology, 7, 488-497. https://doi.org/10.4254/wjh.v7.i3.488

[3] Coppola, N., Stefania, D.P. and Lorenzo, O. (2016) Hepatitis B Virus and C Virus Infection in Healthcare Workers. World Journal of Hepatology, 8, 273-281. https://doi.org/10.4254/wjh.v8.i5.273

[4] Eloumou, S.A.F., Attia, A.K., Assi, C., et al. (2013) Evaluation of the Vaccination Status against Viral Hepatitis B of the Paramedical Staff of the University Hospital Center of Yopougon in Côte d'Ivoire. Review of Medicine and Pharmacy, 3, 346-353.

[5] Kateera, F., Walker, T.D. and Mutesa, L. (2015) Hepatitis B and C Seroprevalence 
among Health Care Workers in Tertiary Hospital in RWANDA. Transactions of the Royal Society of Tropical Medecine and Hygiene, 30, 1-6. https://doi.org/10.1093/trstmh/trv004

[6] Alqahtani, J.M., Abu-Eshy, S.A. and Mahfouz, A.A. (2014) Seroprevalence of Hepatitis B and C Virus Infections among Health Students and Health Care Workers in the Najran Region, Southwestern Saudi Arabia: The Need for National Guidelines for Health Students. BMC Public Health, 14, 577.

https://doi.org/10.1186/1471-2458-14-577

[7] Olusegun, A., Dennis, A.N. and Olowookere, S.A. (2015) Knowledge of Hepatitis B Virus Infection, Immunization with Hepatitis B Vaccine, Risk Perception, and Challenges to Control Hepatitis among Hospital Workers in a Nigerian Tertiary Hospital. Hepatitis Research and Treatment, 2015, Article ID: 439867.

[8] Pietra, V., Kiema, D. and Sorgho, D. (2008) Prevalence of Hepatitis B Virus Markers and Antibodies against Hepatitis C Virus among Nanoro Health District Staff. Vol. 31, Burkina Faso, Science and Technology, Health Science, 53-59.

[9] Thomas, D.L., Stephanie, H. and Gabor, D.K. (1993) Viral Hepatitis in Health Care Personnel at the Johns Hopkins Hospital. Archives of Internal Medicine, 153, 1705-1712. https://doi.org/10.1001/archinte.1993.00410140095011

[10] Afihene, M.Y., Duduyemi, B.M. and A-Tetteh, H.-L. (2015) Knowledge, Attitude and Practices Conserning Hepatitis B Infection, among Healthcare Workers in Bantama, Ghana: A Cross Sectional Study. International Journal of Community Medicine and Public Health, 2, 244-253. https://doi.org/10.18203/2394-6040.ijcmph20150477

[11] Hassan, Awosan, M., Nasir, K.J. (2016) Knowledge, Risk Perception and Hepatitis B Vaccination Status of Healthcare Workers in Usmanu Danfodiyo University Teaching Hospital, Sokoto, Nigeria. Journal of Public Health and Epidemiology, 8, 53-59. https://doi.org/10.5897/JPHE2015.0795

[12] Bathaix, M.F., Bouglouga, O. and Okon, A.J.B. (2015) Practice of Paramedical Staff in Hospitals in Abidjan (Ivory Coast) Facing the Risk of Contamination of the Hepatitis B Virus by Work Accidents. JAHG, 9, 184-188.

[13] Mueller, A., Stoetter, L. and Kalluvya, S. (2015) Prevalence of Hepatitis B Virus Infection among Health Care Workers in a Tertiary Hospital, Tanzania. BMC Infections Diseases, 15, 386-395. https://doi.org/10.1186/s12879-015-1129-z

[14] Kra, O., N’Dri, N. and Ehui, E. (2007) HBs Antigen Prevalence among Blood Donors at the Regional Blood Transfusion Center in Bouaké (Ivory Coast) in 2001. Bulletin de la Société de Pathologie Exotique, 100, 127-129.

[15] Fritzsche, C., Becker, F. and Hemmer, C.J. (2013) Hepatitis B and C: Neglected Diseases among Health Care Workers in Cameroon. The American Journal of Tropical Medicine and Hygiene, 107, 158-164. https://doi.org/10.1093/trstmh/trs087

[16] Braka, F., Nanyunja, M. and Makumbi, I. (2006) Hepatitis B Infection among Health Workers in Uganda: Evidence of the Need for Health Worker Protection. Vaccine, 17, 6930-697. https://doi.org/10.1016/j.vaccine.2006.08.029

[17] Alter, M.J. (2005) The Epidemiology of Hepatitis B Virus Infection in Healthcare Workers in the West and Asia. Hepatitis B Annual, 2, 186-192.

[18] Enel, C., Desgrées, L.A., Yoman, N.T., et al. (2014) Viral Hepatitis B and C in Ivory Coast: The Urgency of Boosting the Fight. Proceedings of 7 th International Francophone Conference on HIV and Hepatitis (AFRAVIH), Montpellier, 27-30 April 2014. 